\title{
CORRESPONDENGE
}

\section{The Management of Needlestick Injuries}

by Dr. med. Heiko Himmelreich, Prof. Dr. rer. med. Holger F. Rabenau, Matthias Rindermann, PD Dr. med. Christoph Stephan, PD Dr. med. Markus Bickel, Prof. Dr. med. Ingo Marzi, PD Dr. med. Sabine Wicker in volume 5/2013

\section{Index Patient's Details Are Important}

Even though needlestick injuries are rarer in nonmedical staff it is important to provide timely medical treatment to affected persons. Uncertainty does, however, exist in incidents outside hospitals. Often, first aiders are exposed to the risk of infection in the setting of car crashes, when they try to free victims from vehicles in spite of bloody injuries and to enable them to have first aid. In spite of gloves and caution, the first aiders may contract injuries and come into intensive contact with the blood from the index persons.

If first aiders have noted down the names of the crash victim and the contact person then it is unproblematic to obtain the index patient's blood. However, if this was omitted in the course of events then it is almost impossible to clarify the situation, because police stations do not give out the names of accident victims. Only when those affected are admitted on an inpatient basis, personal data can be identified among doctors and blood specimens obtained for diagnostic evaluation. Sometimes the first aider's solicitor may be able to get hold of the data of the index person, but this is not certain. If the crash victim has died in hospital it is impossible to obtain patient data or blood.

It should be possible to furnish the trauma surgeon dealing with the case, the leader of the fire brigades, or the Federal Agency for Technical Relief (Technisches Hilfswerk, THW) with the authority to directly gauge the name of the index person in such scenarios and to arrange for a timely blood sample. Ultimately, medical staff are under obligation to safeguard first aiders' prophylaxis even in difficult scenarios.

DOl: 10.3238/arztebl.2013.0420a

\section{REFERENCES Arztebl Int 2013; 110(5): 61-7. \\ Dr. med. Wladimir Teterin \\ Facharzt für Medizinische Mikrobiologie, \\ Pölchow \\ wladimir.teterin@med.uni-rostock.de}

1. Himmelreich H, Rabenau HF, Rindermann M, Stephan C, Bickel M, Marzi I, Wicker S: The management of needlestick injuries. Dtsch

Conflict of interest statement

The author declares that no conflict of interest exists.

\section{In Reply:}

Testing the index patient after a needlestick injury is the prerequisite for optimal medical care for affected medical staff. Awareness of the infectious status of the index patient enables individual therapy and in case of a negative HIV test result prevents potentially serious adverse effect due to post-exposure prophylaxis (HIVPEP).

In routine clinical practice, however, uncertainty often prevails about the extent to which the patient can be forced to have a blood test in order to avert possible harm to the affected staff members.

From our interdisciplinary perspective we regard testing the index patient as appropriate and usually in accordance with their statutory rights (1).

Recent studies have shown that, in addition to the risk of infection, psychosomatic/psychiatric disorders may develop after a needlestick injury (2). A negative test result that is communicated as rapidly as possible unburdens the staff member, whereas a needlestick injury in an infectious patient should be closely monitored in order to avoid psychological or physical disorders, or at least identify and treat them quickly.

The scenarios described by Dr Teterin outside the hospital require a legal clarification as a first step and as a second step, appropriate communication and organization, in order to also treat non-medical staff (for example, first aiders or police) appropriately.

DOI: 10.3238/arztebl.2013.0420b

\section{REFERENCES}

1. Wicker S, Gottschalk R, Spickhoff A, Rabenau HF: HIV-Test nach Nadelstichverletzung: Muss der Indexpatient zugestimmt haben? Dtsch Med Wochenschrift 2008; 133: 1517-20.

2. Green B, Griffiths EC: Psychiatric consequences of needlestick injury. Occup Med 2013; 63:183-8.

3. Himmelreich H, Rabenau HF, Rindermann M, Stephan C, Bickel M, Marzi I, Wicker S: The management of needlestick injuries. Dtsch Arztebl Int 2013; 110(5): 61-7.

\section{PD Dr. med. Sabine Wicker}

Betriebsärztlicher Dienst

Klinikum der Johann Wolfgang Goethe-Universität Frankfurt Sabine.Wicker@kgu.de

\section{Prof. Dr. med. Ingo Marzi}

Klinik für Unfall-, Hand- und Wiederherstellungschirurgie Klinikum der Johann Wolfgang Goethe-Universität Frankfurt

\section{Conflict of interest statement}

PD Dr Wicker has received reimbursement of travel and accommodation expenses and received lecture fees from B Braun, BD, BV-Med, and pfm.

Professor Marzi declares that no conflict of interest exists 